Federal Reserve Bank of Minneapolis

Research Department

\title{
THE CONSUMPTION PROCESS IMPLIED BY AN EFFICIENT CREDIT CONTRACT
}

\author{
Soo-Nam Oh and Edward J. Green*
}

Working Paper 499

June 1992

*Oh, Institute for Monetary and Economic Research, The Bank of Korea; Green, University of Minnesota and Federal Reserve Bank of Minneapolis. This paper is prepared for the 'Debt and Credit' Conference at the LSE. We would like to express our gratitude to the Federal Reserve Bank of Minneapolis for research support, and to the NBER for a dissertation fellowship awarded to Soo-Nam Oh.

The views expressed herein are those of the authors and not necessarily those of the Bank of Korea, the Federal Reserve Bank of Minneapolis or the Federal Reserve System. 


\title{
The Consumption Process Implied by an Efficient Credit Contract
}

\author{
Soo-Nam Oh \\ Institute for Monetary and Economic Research \\ The Bank of Korea \\ and \\ Edward J. Green \\ Federal Reserve Bank of Minneapolis \\ and University of Minnesota
}

June, 1992

This paper is prepared for the 'Debt and Credit' Conference at the LSE. We would like to express our gratitude to the Federal Reserve Bank of Minneapolis for research support, and to the NBER for a dissertation fellowship awarded to Soo- Nam Oh. The views expressed in this paper are those of the authors alone and not necessarily of the Bank of Korea, the Federal Reserve Bank of Minneapolis or the Federal Reserve System. 


\begin{abstract}
In this paper we explain why markets in noncontingent debt securities might be a stable form of market organization for intermediation to households. Efficient-contract allocation might be supported by these markets because households' relationships with their intermediaries do not exactly parallel the explicit form of the noncontingent contracts that they explicitly sign with one another. Also we show that the efficient-contract model can be distinguished from alternative models within the time-series framework that has been widely used to study households' consumption patterns.
\end{abstract}




\section{Introduction}

Households' desire to achieve consumption streams that are less volatile and less risky than are the income streams from which consumption is financed. On their face, the financial transactions that a household could make to accomplish this end are almost exclusively of forms that are tantamount to transactions on debt-security markets-that is, on markets for noncontingent, dated wealth claims. Throughout most of this century, economists' attempts to understand these transactions have focused on the decision problem of the individual household making transactions in a sequence of bond markets. The theoretical study of this decision problem culminates in the rigorous formulation of Friedman's (1957) "permanent-income hypothesis" by Muth (1660), Yaari (1975), Schectman (1975), and Bewley (1977). The use of such decision-theoretic models to inform the study of data began in the 1950's, and such study has steadily expanded and become more sophisticated.

The theorctical research on intermediation among households just described has led to the recognition that the apparent paucity of households' access to markets for statecontingent assets that would insure their income streams constitutes a puzzle. Specifically Bewley (1983) has shown that the assumed decision problem for households cannot be derived from an equilibrium that would be Parcto efficient. ${ }^{1}$ In fact, there is a discrete gap between the highest possible cquilibrium interest rate and the unique Pareto-efficient interest rate. One way of understanding this result is that a non state-contingent asset is being used (via state-contingent trading strategies) to equate households' marginal rates of substitution both across time and across states of nature. A single price per date (that is, an interest rate) does not provide sufficient flexibility to equilibrate the economy efficiently at both of these margins. If one takes seriously the sort of environment that Bewley's and Hellwig's models posit, then one should expect that finanacial innovation would occur so that income-stream insurance would be available to households.

Markets for such income-stream insurance do not exist, of course, although such insurance is provided to a limited extent by public unemployment-insurance schemes. Beginning

1 Bewley credits Martin Hellwig with also having made this observation. 
with Townsend (1982), a number of researchers have paid explicit attention to households' private information about their endowments as a consideration that makes such insurance markets infeasible. These researchers address the question: what form would financial innovation take in such a private-information environment, if a household could write a binding, long-term contract that would commit it to deal exclusively with a single intermediary? ${ }^{2}$ Thomas and Worrall (1990) have shown that a household's marginal utility of wealth under the efficient contract fails to be a martingale, and Green and Oh (1991a) have pointed out that the implication that the efficient contract must implement an allocation that cannot be supported by households' participation in any set of asset markets. Nevertheless, the efficient-contract allocation conforms closely though imperfectly to the martingale characterization of wealth and consumption that has figured prominently in the decision-theoretic approach.

In this paper we offer preliminary answers to two questions that these results raise. First, why have markets for the provision of an efficient income-smoothing contract not replaced markets for debt securities as households' principal arrangement for financial intermediation? Second, given that markets for contracts have not replaced markets for debt securities, and given that both sorts of markets support qualititively similar allocations (that is, allocations in which wealth and consumption are locally well approximated by martingale stochastic processes), what can an efficient-contract model contribute to our understanding of the consumption-savings decisions of actual households?

We provide two complementary answers to the question of why markets for contracts have not replaced markets for debt securities. The first answer is that, while the competitive equilibrium of a debt-securities market will not be Pareto efficient, it may not fall very far short of Pareto efficiency. Since our models abstract from important features of an actual economy such as the real cost of resources used in intermediation, it is easy to imagine why an arrangement that would provide a slight welfare gain in abstraction from these features might not actually be adopted. The second reason is that, for various

${ }^{2}$ See Green and Oh (1991a) for a full discussion of the interpretation of this model and for a fairly comprehensive bibliography of this research. 
reasons including legal and regulatory constraints on enforcement, debt contracts may be more contingent in fact than their explicit form makes clear.

Given the second of these answers, it is an open question whether an efficient-contract model may account better for households' consumption-savings decisions than does a model that takes the explicit form of contracts completely seriously. To investigate this possibility, we compute both the debt-securities and efficient-contracts allocations of a model economy and we study the consumption paths of a typical household in both allocations. We find that the consumption path in the efficient-contract allocation is smoother than is the corresponding path in the debt-securities allocation, and that when consumption along the efficient-contract path is regressed on income and lagged consumption, the coefficients differ from those implied by the debt-securities model in ways that qualtitatively resemble the coefficients that have been obtained from actual panel data.

\section{The model}

We follow Green and Oh (1991a). There are two models, one of which concerns infinitelived households and the other of which is formulated in a two-period setting. In both models households are given a stylized, but detailed, description, and the production sector is just detailed enough to define the equilibria of various institutional arrangements. In the model of infinite-lived households we abstract from the existence of aggregate economic disturbances. This abstraction seems justifiable-Lillard and Willis (1978) and Pischke (1990) have shown that idiosyncratic factors account for far more of the variability in a typical household's consumption than does the business cycle. The two-period model can incorporate a perfectly-forecast aggregate change and thus can serve as a framework for a rudimentary analysis of business-cycle issues. Although the random events confronting an actual household typically might have more to do with its employment opportunities than with its receipt of income simpliciter, both models abstract from labor-supply questions and treat income as exogenous.

Consider first the model of infinite-lived households. This model depicts a continuum of households that are identical ex ante. These households have independent, identically 
distributed random endowments of a perishable composite commodity which is consumed at each date $t=0,1,2, \ldots$. Each household's endowment is i.i.d. as a sequence of random variables indexed by time as well. (That is, the first sense in which endowments are random is as infinite-dimensional endowment vectors indexed by households.) An exact "law of large numbers" is assumed. That is, the aggregate endowment (which is the integral over households of individual endowments) is assumed to be nonstochastic.

Assume for simplicity that a household receives one unit of the composite commodity at any given date with probability $p$, and 0 units with probability $1-p$. (The law of large numbers implies that, at each date, the per capita average endowment will always be exactly $p$ units.) We will often refer to the household's endowment quantity of the good at date $t$ as its income at $t$.

In the ensuing discussion, $X=\left\langle X_{0}, X_{1}, \ldots\right\rangle$ will denote the random sequence of consumption levels enjoyed by a representative household, and $Y=\left\langle Y_{0}, Y_{1}, \ldots\right\rangle$ will denote the random endowment of that household. That is, $X-Y$ will be the net trade of the household.

Suppose that the household has utility function

$$
U\left(\left\langle X_{t}, X_{t+1}, \ldots\right\rangle\right)=\mathrm{E}\left[\sum_{j=0}^{\infty} \beta^{j} W\left(X_{t+j}\right)\right] .
$$

That is, the household has additively separable, time-stationary expected utility. It is assumed that $W$ is strictly concave. The domain of $W$, which represents the set of feasible consumption levels for the household at each date, will be taken to be either $\mathbb{R}$ or else $\mathbb{R}_{+}$.

Assume that aggregate consumption can be shifted over time by the use of a linear technology that can convert 1 unit of the consumption good endowed at date $t$ to $\beta^{t-\tau}$ units of the good for consumption at date $\tau$ (for any $\tau$ before or after $t$ ). By equating the rate of pure time preference to the marginal rate of transformation in this way, we are in effect formulating a partial-equilibrium model. Note that the assumption that future commodities can be transformed for immediate consumption cannot be taken literally (in a closed 
economy, at least). It may be made more palatable by thinking in terms of the economy having a large, steady-state capital stock that must be maintained by investment. This investment can be foregone for a while in order to have higher-than-steady-state consumption until the effects of capital depreciation begin to be felt. Allowing the capital stock to depreciate in this way, with the intention of replenishing it eventually from endowment, is tantamount to conversion of future endowment to present consumption. Another possible interpretation of negative investment would be external borrowing by the inhabitants of an open economy.

Assume that a household learns about its own income contemporaneously with its receipt, and that a household's income and consumption levels are private information that the household can report to others, but that cannot be directly verified. Assume that a household's use of the intertemporal-transformation technology is public information and that this use may be limited by contract, or equivalently assume that individual households must obtain access to the technology through the intermediary. Finally, assume that households can bind themselves to long-term participation in a contractual arrangement that has the potential to dictate an ex post welfare level lower than autarky under some circumstances.

Now suppose that the endowment of a representative household is $Y=\left\langle Y_{0}, Y_{1}, \ldots\right\rangle$ and that this household is supposed to receive consumption $X=\left\langle X_{0}, X_{1}, \ldots\right\rangle$. If the differences between consumption and income at all dates were transformed into the date 0 commodity using the technology of the economy, then the expected output of this process would be $\mathrm{E}\left[\sum_{t=0}^{\infty} \beta^{t}\left(X_{t}-Y_{t}\right)\right]=\mathrm{E}\left[\sum_{t=0}^{\infty} \beta^{t} X_{t}\right]-\frac{p}{1-\beta}$. This output quantity is the net cost of providing $X$ to the household.

A contract is a sequence of rules, one for each date, that determines a net trade for each household as a function of the household's past and current reports about its income. Let $b_{0}$ denote the amount of consumption that will be transferred to a household according to such a rule if the household reports having received no income at date 0 , and let $b_{1}$ be the amount that will be transferred to the houschold if it reports having received one unit of income at date 0 . (These transfers may be either positive or negative.) Let 
$Z_{0}=\left\langle Z_{1}^{0}, Z_{2}^{0}, \ldots\right\rangle$ and $Z_{1}=\left\langle Z_{1}^{1}, Z_{2}^{1}, \ldots\right\rangle$ be the best random consumption streams that the household can obtain from date 1 forward by responding strategically to the contract after having initially reported income of 0 or 1 respectively at date 0 . (By the Bernoulli structure of endowments and the time separability of preferences, the household's optimal strategy from date 1 forward does not depend on its actual income at date 0 .)

In a closed economy, the problem of designing the ex ante efficient contract can be formulated as: maximize $U(X)$ subject to the incentive-compatibility constraints

$$
W\left(b_{0}\right)+\beta U\left(Z_{0}\right) \geq W\left(b_{1}\right)+\beta U\left(Z_{1}\right) .
$$

and

$$
W\left(1+b_{0}\right)+\beta U\left(Z_{0}\right) \leq W\left(1+b_{1}\right)+\beta U\left(Z_{1}\right) .
$$

and subject also to the materials-balance constraint that the net cost of $X$ must not exceed zero.

For any $u$ in the range of $U$, let $C(u)$ denote the minimum net cost (in the sense just defined) of providing the household with a consumption stream $X$ such that $U(X)=$ $u$ and such that the incentive-compatibility conditions (2) and (3) hold, and such that their analogues hold at all dates and after all possible histories of income reports. ${ }^{3}$ (For example, $C^{-1}(0)$ is the utility level that an efficient contract achieves for the representative household.) Suppose that $U(X)=u$, that $X$ is implemented by an incentive-compatible contract, and that the net cost of $X$ is $C(u)$. Then, in the notation that has been defined above, $C$ satisfies the functional equation

$$
\begin{aligned}
C(u) & =\mathrm{E}\left[b_{Y_{0}}+\beta C\left(U\left(Z_{Y_{0}}\right)\right)\right] \\
& =p\left[b_{1}(u)+\beta C\left(v_{1}(u)\right)\right]+(1-p)\left[b_{0}(u)+\beta C\left(v_{0}(u)\right)\right] .
\end{aligned}
$$

The model just described is well adapted to studying time-series features of the efficient-contract allocation, but a two-period version of the model which we will describe

${ }^{3}$ We will often assume implicitly that $U(X)=u$, and that quantities derived by use of this assumption are implicitly functions of $u$. 
now has several advantages. The assumption that there are only two income levels is relaxed (as in Thomas and Worrall (1990)). Finite lower bounds on consumption are imposed. The technology can transform present consumption to future consumption but not vice versa.

A continuum of households are identical ex ante. There is a single kind of consumption good that is available at two dates. The endowment at date 1 is random and is i.i.d. across households. For simplicity, it will be assumed that there are only finitely many levels of the first-period endowment: $y_{1}<y_{2}<\ldots<y_{n}$. A household receives each level $y_{i}$ of endowment with probability $p_{i}>0$. Ex post, this same proportion $p_{i}$ of households will have received endowment level $y_{i}$ in any state of the world. It will be assumed that all households receive a deterministic endowment of $z \geq 0$ at date 2. A household must have nonnegative consumption at each date. This consumption is achieved by means of a net trade that is a function of the household's ex post endowment. That is, a household receiving an endowment level $y_{i}$ at date 1 will enjoy a consumption level $y_{i}+b_{i}$ at that date and $z+c_{i}$ at date 2 . In that event, the household will achieve a utility level $W\left(y_{i}+b_{i}\right)+\beta W\left(z+c_{i}\right)$, where $\beta$ is a discount factor. $W$ is assumed to be strictly concave, strictly increasing, and differentiable.

It is envisioned that there is an intermediary (or a social planner) who offers a contract or schedule $\Gamma=\left(\left(b_{1}, c_{1}\right), \ldots,\left(b_{n}, c_{n}\right)\right)$ of feasible net trades to households. Feasibility entails that, for all $i$ belonging to $\{1, \ldots, n\}$,

$$
b_{i} \geq-y_{i} \text { and } c_{i} \geq-z \text {. }
$$

It is also envisioned that the intermediary must rely without verification on households' reports about their ex post endowments. This informational asymmetry imposes the following incentive-compatibility constraint on the contract for all $i$ and $j$.

$$
\text { If } b_{j} \geq-y_{i} \text {, then } W\left(y_{i}+b_{i}\right)+\beta W\left(z+c_{i}\right) \geq W\left(y_{i}+b_{j}\right)+\beta W\left(z+c_{j}\right) \text {. }
$$

The intermediary has access to a constant-returns-to-scale technology that can convert one unit of date- 1 consumption into $R$ units of date- 2 consumption. Thus, a contract is 
technically feasible for the intermediary to offer if it satisfies

$$
\sum_{i=1}^{n} p_{i} b_{i} \leq 0 \text { and } \sum_{i=1}^{n} p_{i}\left(b_{i}+R^{-1} c_{i}\right) \leq 0 .
$$

Note that the first inequality in (7) is a nonnegativity constraint on investment, and that $R$ can be considered to be the gross interest rate implied by the marginal rate of transformation.

Given that it commits itself ex ante to participate in an incentive-compatible contract $\Gamma$, the expected utility of a household is

$$
U(\Gamma)=\sum_{i=1}^{n} p_{i}\left\{W\left(y_{i}+b_{i}\right)+\beta W\left(z+c_{i}\right)\right\} .
$$

We consider a contract $\Gamma^{*}\left(\left(b_{1}^{*}, c_{1}^{*}\right), \ldots,\left(b_{n}^{*}, c_{n}^{*}\right)\right)$ that maximizes $U$ subject to constraints (5), (6) and (7). We have shown that, under the assumption that $W$ exhibits non-increasing absolute risk aversion, such a deterministic contract will be efficient even if randomization is feasible ( $\mathrm{Oh}$ and Green 1991).

Both the infinite-horizon model and the two-period model that we have described here can be solved numerically. The results that we report below have been obtained in this way. Full details of the solution procedure are given in Studies in Efficient Contracts (Oh, 1991).

\section{Debt-securities markets may be nearly efficient.}

As we have mentioned in the introduction, it is known that the efficient-contract allocation of the two-period model cannot be supported by competitive trade in a debtsecurities market (Green and Oh, 1991a, pp. 897). Competitive debt-securities equilibrium does satisfy the incentive-compatibility and technical-feasibility constraints (5)-(7), though, so it supports an allocation that is feasible in the private-information environment of the model. A natural question is, just how serious does the debt-securities equilibrium allocation depart from ex-ante efficiency? 
We will answer this question by adapting Debreu's (1952) coefficient of resource utilization to this environment. This welfare measure is essentially a general-equilibrium version of the equivalent-variation measure. Let $\mathcal{E}=\langle Y, Z\rangle$ be the endowment in the twoperiod economy described at the end of the last section. For $0<\alpha \leq 1$, let $\gamma(\alpha)$ be the expected-utility level that the representative household receives from the efficient-contract allocation of the economy with endowment $\alpha \mathcal{E}$ (which is a scalar multiple of the random endowment in the original economy). Let $\delta$ be the expected-utility level that the representative household receives from the debt-securities-equilibrium allocation of the economy with endowment $\mathcal{E}$. Define the coefficient of resource utilization, $\rho_{d}$, to be the infimum of the set of $\alpha$ such that $\gamma(\alpha) \geq \delta$. The coefficient of resource utilization for autarky, $\rho_{a}$, is defined analogously.

We would like to know how large is the welfare loss in the debt-securities equilibrium relative to the welfare loss in autarky, where both losses are measured relative to the efficient-contract allocation and are expressed in terms of the coefficient of resource utilization. That is define the loss ratio to be $\lambda=\left(1-\rho_{d}\right) /\left(1-\rho_{a}\right)$.

We compute this resource-utilization coefficient for twelve economies that differ with respect to the specification of both the households' utility function and also the endowment. We consider three widely used functional forms of a household's instantaneous utility function: $\log$, constant absolute risk aversion (CARA, $-e^{-\gamma c}$ ), and constant relative risk aversion (CRRA, $\left.\frac{1}{1-\sigma}\left(c^{1-\sigma}-1\right)\right)$. We choose preference parameters as follows; discount factor $(\beta)=.96$, absolute risk aversion parameter $(\gamma)=1$ for CARA utility function, and relative risk aversion parameter $(\sigma)=1.5$ for CRRA utility function. Note that all of these functional forms rule exclude boundary consumption in an efficient allocation.

We assume $\beta R=1$, which is equivalent to the assumption that a representative household and an intermediary have a common discount factor. This last assumption is adopted with a partial-equilibrium model in mind.

For each utility-function specification, we consider the four endowments that are specified in Table 1. The results of our study are shown in Table 2. The welfare-loss ratio $\lambda$ for the twelve economies that we study rang from 0.08 to 0.42 . Between these ex- 
tremes, $\lambda$ is between 0.1 and 0.2 in seven economies and $\lambda$ is between 0.2 and 0.3 in three economies. With one exception, the welfare loss in the efficient-contract allocation is less than one-fifth of the welfare loss in autarky when households' preferences are paramatrized by constant-relative-risk-aversion utility functions. With one exception, the welfare loss in the efficient-contract allocation is less than one-third of the welfare loss in autarky when households' preferences are paramatrized by a constant-absolute-risk-aversion utility function. Regarding these ratios, one could take either the position that from the debtsecurities equilibrium there is substantial room for improvement or the position that the debt-securities equilibrium achieves as high a welfare level as can realistically be expected in an incomplete-information environment. The latter view could be supported by the argument that debt-securities equilibrium is implemented by a simple, robust institutional framework while the efficient contract might potentially be complicated and fragile. Someone who accepts the latter view will not be surprised that a debt-securities market is what we observe in the actual economy.

\section{Debt securities may be state contingent in practice}

Another explanation of why debt contracts without state-contingency clauses are so prominent in households' financial arrangements is that these contracts may be more state contingent in practice than their explicit form indicates. Default rates on most categories of loans to households are low, but default rates do not necessarily provide an accurate picture of how loans are administered. A loan is declared to be in default when there has been a breakdown of negotiations between the lender and the borrower regarding terms and schedule of repayment. Thus default is a very different matter from renegotiation. As numerous models in the recent economic-theory literature show, contract renegotiation may be prevalent without a bargaining impasse ever occurring in equilibrium. In the case of loan contracts, then, state contingency may be achieved via renegotiation rather than through explicitly written provisions. Such renegotiation may particularly be encouraged by political and regulatory actions during business-cycle downturns. We have argued this case elsewhere in detail (Green and Oh, 1991b). The efficient-contract model appears to 
fit several episodes of nineteenth- and twentieth-century U.S. banking history that are difficult to understand in terms of the debt-securities-equilibrium model, and it also seems to explain the widely-held assessment that non-price rationing of credit is more likely to occur in severe recessions than at other times.

If there is indeed a substantial difference between how contracts between intermediaries and households are overtly written on the one hand, and how those contracts are actually administered on the other hand, then there is not much reason a priori to prefer the debt-securities-equilibrium model to the efficient-contract model as a model of allocation of dated, state-contingent consumption among households. It is necessary to compare the two models with respect to their ablity to account for observations of actual economies. Besides the preliminary attempt that we have just described to confront the efficient-contract model with macroeconomic observations, we have begun to examine how well the model can account for longitudinal panel data on households' consumption patterns.

To do this, we began by numerically solving the equation (4) for the cost function $C$. We did this by implementing a recursive algorithm that Green (1987) and Thomas and Worrall (1990) have shown to converge. The efficient contract is determined from $C$ as described in those papers. That is, the values of $b_{0}(u), b_{1}(u), v_{0}(u)$ and $v_{1}(u)$ are found for each $u$ by minimizing the right-hand side of (4) subject to incentive-compatibility constraints (that is, subject to the constraints derived from (2) and (3) by replacing $U(Z-i)$ with $\left.v_{i}(u)\right)$ and subject to the martingale-expected-utility constraint that

$$
u=p\left[W\left(1+b_{1}(u)\right)+\beta v_{1}(u)\right]+(1-p)\left[W\left(b_{0}(u)\right)+\beta v_{0}(u)\right] .
$$

Note that we have not imposed a non-negativity constraint on the household's consumption.

We performed this computation for an economy with $\frac{p=1}{2}, \beta=.96$, and $\frac{R=1}{\beta}$ and in which $W$ is a constant-relative-risk-aversion utility function with parameter $\sigma=1.5$.

The next step was to generate Bernoulli endowment paths, and then to calculate the consumption paths that the efficient contract assigns to households having those endowment realizations. Three of these consumption paths are depicted in Figure 1. Households 
1,2 , and 3 receive income in 111,100 , and 89 out of two hundred periods respectively. Only about one household in twenty would receive income in fewer periods than does Household 3, and the consumption path of this household dips only briefly below zero. This observation suggests that our failure to take account of the nonnegativity constraint may not be too serious a misspecification.

We also computed the debt-securities-equilibrium consumption path for Household 2. To be precise, we followed Hall (1978) and Sargent (1987) who study "permanent-income" consumption in a stochastic-optimization framework. When a representative household maximizes its expected utility subject to the sequence of budget constraint

$$
f\left(v_{t+1}\right)=R\left(f\left(v_{t}\right)+y_{t+1}-c_{t+1}\right) \text { for } t=0,1, \ldots,
$$

under the quadratic utility assumption, the consumption plan is summarized by ${ }^{4}$

$$
E_{t} c_{t+j}=c_{t}, \forall j \geq 1
$$

and

$$
c_{t}=\left(1-R^{-1}\right)\left(f\left(v_{t-1}\right)+\frac{z}{1-\beta}\right) .
$$

The efficient-contract and "permanent-income" consumption paths are shown together in Figure 2. The two paths remain close together throughout their length. However, in this example the efficient-contract path seems systematically to shrink consumption toward its mean value from the "permanent-income" path. What is actually happening is that the efficient-contract consumption innovation due to a given income innovation is smaller than the corresponding "permanent-income" consumption innovation.

An alternative way to characterize the difference between the efficient-contract and debt-securities-equilibrium consumption paths is in terms of regression of consumption on past consumption and income. Consider a household's consumption in the debt-securitiesequilibrium allocation as a function of the household's current and past income. Suppose that consumption in the immediately preceding period is a regressor of current consumption. Then, given the assumed Bernoulli process of income, both immediate past income

\footnotetext{
${ }^{4}$ For more details of the derivation, refer to Sargent (1987).
} 
and also consumption prior to the immediate past period should have zero coefficients if they are also regressors.

When these regressions are performed on the income-consumption path of Household 2 , the following results are obtained. Note that nonzero coefficients on both income and lagged consumption are obtained. ${ }^{5}$

$$
\begin{gathered}
c_{t}=.0060+.9889 c_{t-1}+.0075 y_{t-1} \\
(.0093)(.0081) \quad(.0012) \\
R^{2}=0.9869 \\
c_{t}=.0165+1.3378 c_{t-1}-.3515 c_{t-2} \\
(.0095) \quad(.0669) \quad(.0666) \\
R^{2}=.9863
\end{gathered}
$$

\section{Conclusion}

In this paper we have done two things. First, we have explained why markets in noncontingent debt securities might be a stable form of market organization for intermediation to households. Moreover, summarizing Green and Oh (1991b), we have argued that the efficient-contract allocation might be supported by these markets because households' relationships with their intermediaries do not exactly parallel the explicit form of the noncontingent contracts that they explicitly sign with one another. Second, we have continued the analysis of the observational consequences of the efficient-contract model that we began in recent work (Green and Oh, 1991a). There we used the two-period model studied above to show that the efficient-contract model would be observationally distinguishable in principle from both the debt-securities-equilibrium model and also the ad-hoc "liquidity constraint" models to which we have just referred. In the present paper, we have shown

${ }^{5}$ (Durbin's $h$ statistic for the first regression is -0.172 . 
that this program can be implemented within the time-series framework that has been widely used to study households' consumption patterns.

Beginning with Hall and Mishkin (1982), a number of economists have performed regressions of this sort on actual panel data. They have reported nonzero coefficients on variables related to income and lagged consumption. On this basis they have expressed reservations about the debt-securities-equilibrium model. These economists have tended to propose alternative theories that imply the inefficiency of allocation from an ex-ante perspective, and that suggest the irrationality of households as explanations of this inefficiency. On the basis of our work to date, we believe that the efficient-contract model provides a plausible, empirically meaningful alternative to such explanations. 


\section{References}

Bewley, T. (1977), "The Permanent Income Hypothesis: A Theoretical Formulation," Journal of Economic Theory, 16, 252-292.

Bewley, T. (1983), "A Difficulty with the Theory of Money," Econometrica, 51, 1485-1504.

Debreu, G. (1952), "The Coefficient of Resource Utilization," Econometrica, 20, 273-291.

Friedman, M. (1957), A Theory of the Consumption Function (Princeton: Princeton University Press).

Hall, R.E. (1978), "Stochastic Implications of the Life Cycle-Permanent Income Hypothesis: Theory and Evidence", Journal of Political Economy, 86, 971-987.

Green, E.J. (1987), "Lending and the Smoothing of Uninsurable Income," in Contractual Arrangements for Intertemporal Trade, E.C. Prescott and N. Wallace, eds. University of Minnesota Press.

Green, E.J. and Oh, S.-N. (1991a), "Contracts, Constraints and Consumption," Review of Economic Studies, 58 883-900.

Green, E.J. and Oh, S. N. (1991b), "Can a 'Credit Crunch' Be Efficient?," Federal Reserve Bank of Minneapolis Quarterly Review, 15, 3-17.

Hall, R.E. (1978), "Stochastic Implications of the Life Cycle-Permanent Income Hypothesis: Theory and Evidence," Journal of Political Economy, 86, 971-987.

Hall, R.E. and Maskin, R.S. (1982), "The Sensitivity of Consumption to Transitory Income: Estimates from Panel Data on Households", Econometrica, 50, 461-481.

Lillard, L.A. and Willis, R.J. (1978), "Dynamic Aspects of Earning Mobility", Econometrica, 46, 985-1012.

Muth, J. (1960), "Optimal Properties of Exponentially Weighted Forecasts," Journal of the American Statistical Association, 55, 299-3096.

Oh, S. N. (1991), Studies in Efficient Contracts, University of Pittsburgh dissertation. 
Pischke, J.-S. (1990) "Individual Consumption, Incomplete Information and Aggregate Consumption," (mimeo, Princeton University).

Sargent, T.J. (1987), Macroeconomic Theory, 2nd ed., (Academic Press, New York).

Schechtman, J. (1975), "An Income Fluctuation Problem," Journal of Economic Theory, $12,218-241$.

Thomas, J. and Worrall, T. (1990), "Income Fluctuation and Asymmetric Information: An Example of a Repeated Principal-Agent Problem", Journal of Economic Theory, 51, 367-390.

Townsend, R.M. (1982), "Optimal Multiperiod Contracts and the Gain from Enduring Relationships under Private Information", Journal of Political Economy, 90, 11661186 .

Yaari, M. (1975), "A Law of Large Numbers in the Theory of Consumer's Choice under Uncertainty," Journal of Economic Theory, 12, 202-217. 
Figure 1: Three Sample Paths of the Efficient-Contract Consumption Process

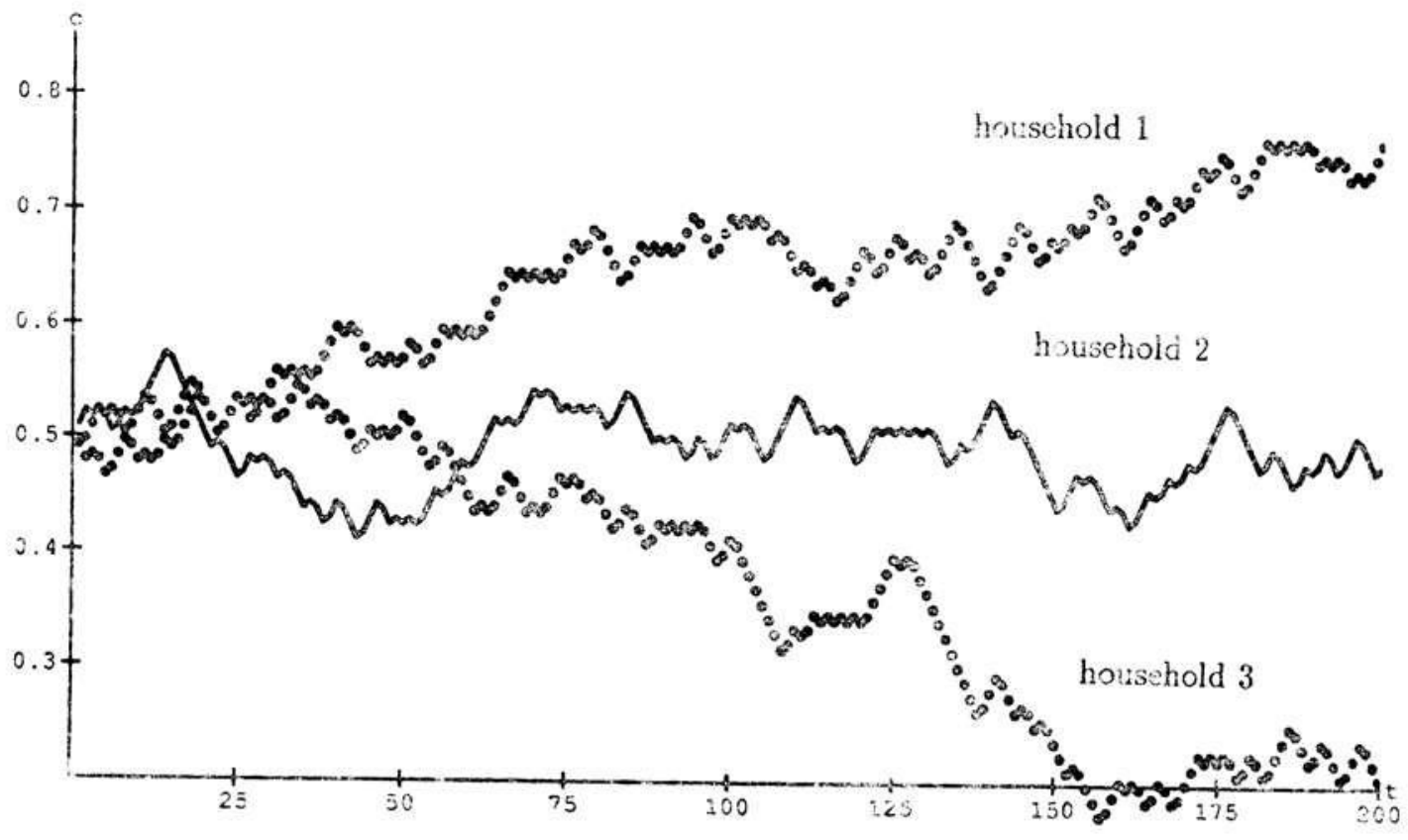

Figure 2: Comparison of Efficient-Contract and Debt-Securities Consumption Processes

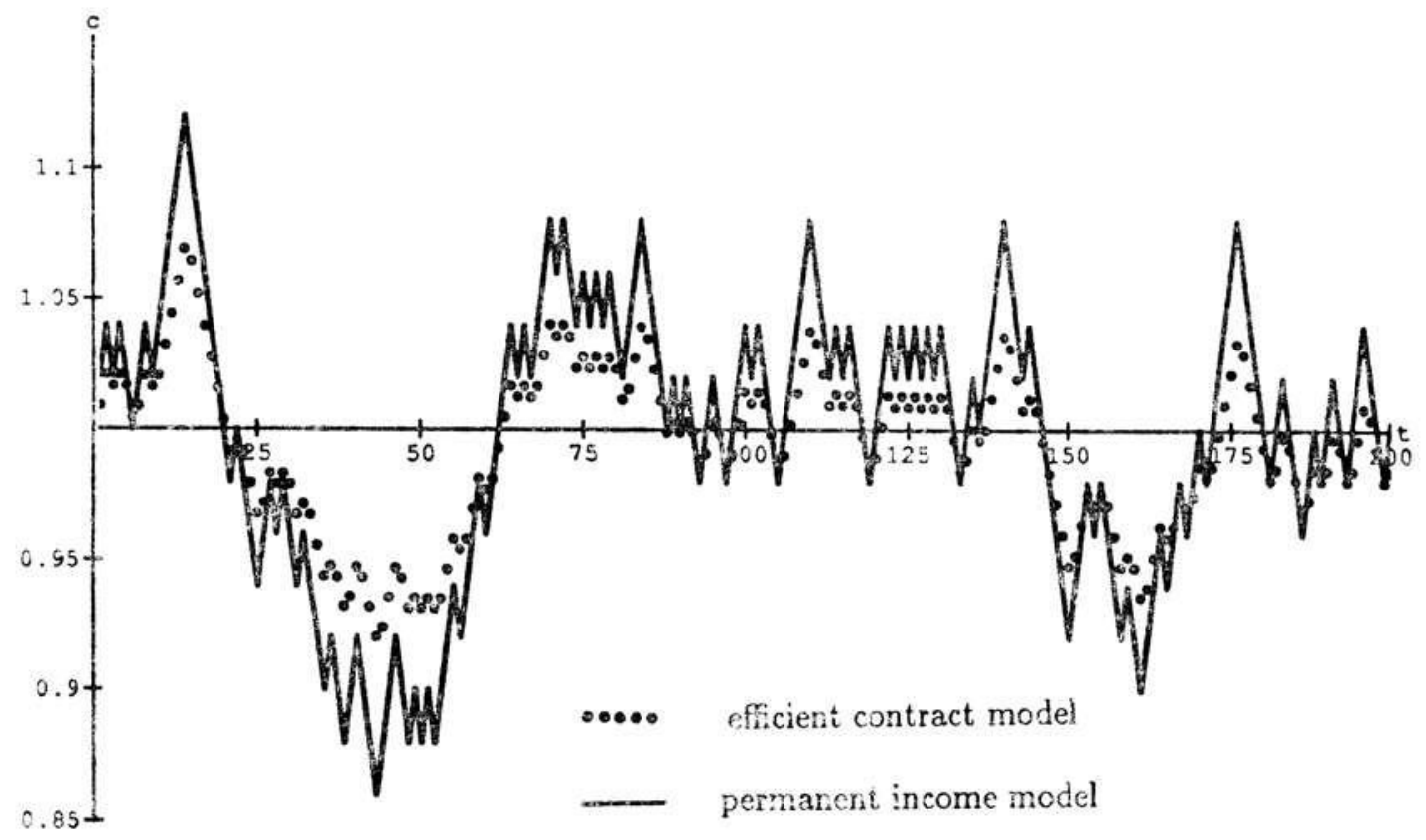


Table 1 : Specification of Endowments

$\begin{array}{lllll}\text { Income(Prob.) } & \text { Endowment } 1 & \text { Endowment } 2 & \text { Endowment } 3 & \text { Endowment 4 } \\ y_{1}\left(p_{1}\right) & 1(0.2) & 1(0.1) & 1(0.2) & 2.0(0.1) \\ y_{2}\left(p_{2}\right) & 2(0.2) & 2(0.2) & 2(0.2) & 2.5(0.2) \\ y_{3}\left(p_{3}\right) & 3(0.2) & 3(0.4) & 3(0.2) & 3.0(0.4) \\ y_{4}\left(p_{4}\right) & 4(0.2) & 4(0.2) & 4(0.2) & 3.5(0.2) \\ y_{5}\left(p_{5}\right) & 5(0.2) & 5(0.1) & 5(0.2) & 4.0(0.1) \\ \mathrm{z} & 3 & 3 & & 3\end{array}$

Note: For all economies, $\beta=.96$ and $\mathrm{MRT}=1 / \beta$.

\section{Explanation}

We construct Endowment 1, our base endowment, by uniformly distributing income at date 1 over five levels and the by setting the income level at date 2 equal to the average income level at date 1. In all economies having this endowment, aggregate investment is zero at the efficient allocation. Date-1 income has the same probability distribution in Endowment 3 as in Endowment 1, but income at date 2 is specified to be sufficiently low that the efficient level of aggregate investment will be positive for all of the utility-function specifications that we consider. Economies 2 and 4 are constructed for the purpose of comparing the effect of uncertainty of the endowment on allocation. Note that uncertainty is getting smaller from Endowment 1 to 2, and to 4 . Also note that, regardless of the households' utility function, the consumption bundles assigned in the debtsecurities-equilibrium allocation to households with any specific income level are the same whether the economy has Endowment 1, Endowment 2, or Endowment 4. This is because each household maximizes its utility by debt-security trade after receiving its own endowment, that is, there is no risk sharing among households in the debt-securities equilibrium. 
Table 2: Efficiency and Investment

Endowment 1

\begin{tabular}{|c|c|c|}
\hline & Utility Functions & \\
\hline $\log c$ & $-e^{-c}$ & $-2\left(\frac{1}{\sqrt{c}}-1\right)^{*}$ \\
\hline
\end{tabular}

\begin{tabular}{lllll}
$\lambda$ & & 0.1157 & 0.2999 & 0.1508 \\
$\rho$ & DS & 0.9947 & 0.9594 & 0.9878 \\
\multirow{2}{*}{ Investment } & Autarky & 0.9542 & 0.8646 & 0.9191 \\
& EC & $0^{-}(-0.1207)$ & $0^{-}(-0.2053)$ & $0^{-}(-0.1973)$ \\
& DS & 0 & 0 & 0
\end{tabular}

Endowment 2

\begin{tabular}{lllll}
$\lambda$ & & 0.1165 & 0.2867 & 0.1501 \\
$\rho$ & DS & 0.9969 & 0.9754 & 0.9929 \\
\multirow{3}{*}{ Investment } & Autarky & 0.9734 & 0.9142 & 0.9527 \\
& EC & $0^{-}(-0.0754)$ & $0^{-}(-0.1456)$ & $0^{-}(-0.1012)$ \\
& DS & 0 & 0 & 0
\end{tabular}

Endowment 3

$\lambda$

$\rho$

Investment

Endowment 4

$\lambda$

$\rho$

Investment

Investment

0.1774
0.9917
0.9532
0.1178
0.2449

DS

Autarky

EC

DS

DS
Autarky
EC
DS

